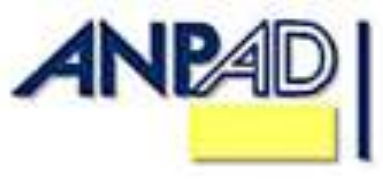

\author{
Available online at \\ http://www.anpad.org.br/bar \\ BAR, Rio de Janeiro, v. 12, n. 2, art. 5, \\ pp. 209-228, Apr./June 2015 \\ http://dx.doi.org/10.1590/1807-7692bar2015140076

\title{
Profiling the Buzz Agent: Product Referral and the Study of Social Community and Brand Attachment
}

Danny Pimentel Claro Insper Instituto de Ensino e Pesquisa

Adriana Bruscato Bortoluzzo Insper Instituto de Ensino e Pesquisa

Received 17 November 2014; received in revised form 18 May 2015 (this paper has been with the author for two revisions); accepted 18 May 2015; published online 12 June 2015.

Editor's note. Kenny Basso served as Action Editor for this article. 


\begin{abstract}
The buzz agent is any consumer perceived by others as a source of product referral. Previous literature in word of mouth (WOM) has looked into characteristics of individuals who successfully persuade others to choose a brand. While there have been studies in this field, the literature is still scattered and little has been done to profile the consumer playing the buzz-agent role. We aim to deepen our understanding about the consumer who must be recruited as a buzz agent by a firm in a WOM marketing (WOMM) initiative. The proposed profile is comprised of three key characteristics: the consumer's position in the social community, nature of ties in the community and brand attachment. We tested our hypotheses with a survey of 542 consumers from a controlled population. Rather than relying on self-reported questions about referral behavior, we asked respondents in the population to name the individuals to whom the respondents go to obtain information to help pick a brand. This accurately pinpoints which individuals fit the profile of a buzz agent. Results show that buzz agents are popular in their social community (friends and tech experts), carry dissimilar brands as target consumers and are product experts. Our study identifies a profile of consumers that helps firms select buzz agents for WOMM initiatives.
\end{abstract}

Key words: buzz agent; word of mouth; social community; brand. 


\section{Introduction}

We define for our study that a buzz agent refers to any consumer perceived by others as a source of product referral. In a consumer-to-consumer context, no consumers are equal. Some - the buzz agents - have a disproportionate ability to influence others. Increasingly, firms recognize that such consumers need to be identified and recruited to be part of word of mouth marketing (WOMM). A previous study showed a firm's success in promoting a brand by recruiting a few college students from popular fraternities to try out products and implicitly endorse the brand (Dye, 2000). WOMM is the intentional influencing of consumer-to-consumer communications by firms' marketing initiatives (Kozinets, Valck, Wojnicki, \& Wilner, 2010) such as social media marketing (Schmitt, Skiera, \& Van den Bulte, 2011), viral marketing (Court, Gordon, \& Perrey, 2005), endorsement campaign (Dye, 2000) and blogger sponsorship (Cheema \& Kaikati, 2010). These initiatives stimulate buzz agents to convert other consumers into users. Even though these are important marketing initiatives, firms still strive to recruit buzz agents because it is hard to profile them.

The buzz agent profile can be built into three characteristics as previous studies disconnectedly suggest. First, buzz agents influence others by capitalizing on who they know and how they are part of communities (e.g. Murphy, Mascardo, \& Benckendorff, 2007). The rapid growth of communication phone, instant messaging, social networks - means increased speed, reach and intensity of relationships in different communities. These communities have even further empowered buzz agents to spread their opinions about products and advocate on behalf of brands. Second, buzz agents set up community ties to help them convey the message across a number of potential consumers (e.g. Weiss, Lurie, \& Macinnis, 2008). Buzz agents form ties with friends that look alike and combine ties in different community domains. By forming ties with people like them and with friends that are also in the technology community, buzz agents benefit from common backgrounds and familiarity that foster fluid information flow. Third, all underlying associations of brands helps buzz agents to promote themselves as sources of product referral (e.g. Haenlein \& Libai, 2013; Kozinets et al., 2010). Consumers rely on other consumers that know the brand and have used the products and services of that brand. Consumers who own desired brands and show convincing knowledge about products are regarded as buzz agents. These three key characteristics support a recruiting and selection system of consumers with potential to become a buzz agent for firms' WOMM.

We aim to study three key characteristics in the current context of booming social communities. Consumers have a need to come together and share information for the purpose of work and entertainment, which always has a component of functionality to it. For instance, a consumer decides to buy a new phone that has a great functional impact on day-to-day matters as well as a great impact on the consumer's social life. In order to tackle such an aim, we profile the buzz agent by gathering information about two key consumer characteristics (social community and brand attachment) and include demographic controls as well as narcissism to control for personality traits. Data from a survey with 542 consumers of a controlled population provided evidence to test two hypotheses of our buzz agent profile.

This study contributes to WOMM literature in two ways. First, our profile integrates different characteristics of the buzz agent, which include the social relationships with friends in a community, the composition of such communities and brand expertise and similarity. The extant research devoted attention to these characteristics in isolation. We combine them in a comprehensive integrated profile to deeper our understanding of the special consumer that we call a buzz agent. For managers, the profile elucidates relevant selection criteria of consumers to become the focal point of the marketing effort. Second, we contribute to WOMM literature by developing an unbiased method to identify consumers to be studied as buzz agents. Rather than relying on self-reported questions about referral behavior, we asked respondents in a controlled population to name the particular consumers who they rely upon to gather information and choose a product. People in the same community are able to accurately identify the buzz agent, who are those consumers to study for the relevant characteristics. 
The next section of the paper reviews the literature used to build our hypotheses. We then present our hypotheses and build the argument based on relevant literature in the WOM field. Next, we present our research method as well as our measurement instrument, followed by the results of the regression equations. Finally, we discuss the results and put forward managerial implications and suggestions for future research.

\section{Word of Mouth Marketing and the Role of Buzz Agent}

Word-of-mouth (WOM), which refers to consumer-to-consumer communication to spread the word about a brand (i.e. product or service), has been recognized for quite some time as a powerful means to disseminate information about products and services (Brooks, 1957). A seminal study of WOM behavior showed that when a target consumer realizes that a firm is communicating by means of a friend consumer or an unbiased speaker, the target consumer relaxes and is more likely to accept the firm's assertions about the product (Dichter, 1966). Early studies in the field consistently established WOM as a meaningful social force that influences marketing thought and practice (Chevalier \& Mayzlin, 2006). The consumer's preference for a product does not happen randomly. It generally involves receiving information about someone else's experience or expertise. Such an interpersonal communication triggers a sociological-involvement mechanism that truly motivates consumers to purchase a product (Goldenberg, Han, Lehmann, \& Hong, 2009).

Recent studies in the field of WOM provided evidence for firms to engage in WOMM initiatives. For example, Schmitt, Skiera and Van den Bulte (2011) found that referral programs generate consumers that are more profitable in both the short and long term. Another study focused on high-uniqueness consumers, who are the ones that prefer to differentiate themselves from others of their respective reference groups (i.e. communities) (Cheema \& Kaikati, 2010). This study showed that such high-uniqueness consumers were more likely to recommend products which they themselves consumed (Cheema \& Kaikati, 2010). Bughin, Doogan and Vetvik (2010) proposed using word-ofmouth equity as an index of a brand's power to generate messages that influence consumers' purchasing decisions. WOMM initiatives are illustrated in several other studies that describe the effects of firms' stimulus to consumer-to-consumer communication and assess the positive effects on purchasing decisions (e.g., Chevalier \& Mayzlin, 2006; Murphy et al., 2007; You, Vadakkepatt, \& Joshi, 2015).

From the consumer point of view, the perceived costs and benefits of spreading the opinion about a brand will motivate the decision to engage in consumer-to-consumer communication (Frenzen \& Nakamoto, 1993). Some consumers may proactively play the role of buzz agents, which often leads them to become known as market mavens or opinion leaders (King \& Summers, 1970). These buzz agents are motivated by a greater sense of obligation to pass on information, a desire to help others, and a feeling of pleasure arising from telling others about products (Cheema \& Kaikati, 2010). Other consumers may engage in WOM behavior to justify their decisions, generate approval, and achieve social status (Gatignon \& Robertson, 1986). In essence, the underlying motivation of buzz agents is to generate WOM as a type of social influence.

The buzz agents are individuals that have some deep knowledge about a brand and are eloquent in passing on the information. In the context of rapid and intense information sharing activity by all different means (e.g. digital and face to face), it becomes essential for firms to profile the consumer more likely to successfully engage in a WOMM. We suggest a profile that encompasses who the buzz agent knows - by looking at social relationships in communities - and what the buzz agent knows by looking at their expertise and experience with the brand. From this starting point, we move towards a model to study the buzz agent profile that is depicted in Figure 1. 


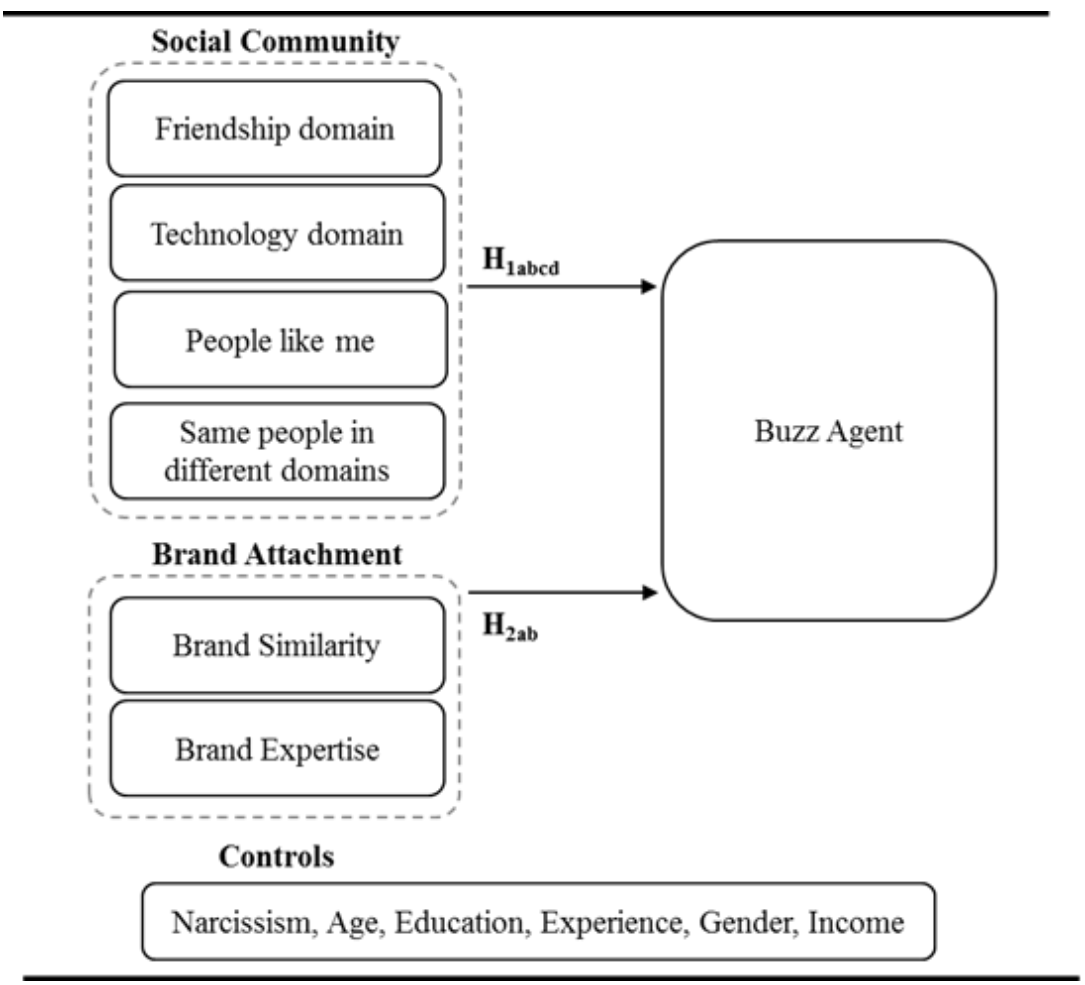

Figure 1. The Model to Study Buzz Agent Profile

\section{Towards a Profile of Buzz Agents}

The WOM literature refers to community as a locus for propagation or diffusion as a consumer passes on information or opinion to other consumers (e.g. Goldenberg et al., 2009). Nowadays, consumers are more and more interconnected and create powerful invisible clubs of social support that dominate the adoption (or rejection) of products, ideas and styles (Gatignon \& Robertson, 1986; Nam \& Kannan, 2014; Patterson, 2007). Psychologists show that the community development process depends on the internalization of norms and values from people in the surroundings, which serve as an internal benchmark (e.g. Mazar, Amir, \& Ariely, 2008). Compliance with the internal values provides positive feedbacks that nurture the relationships between individuals. The weight consumers give to their social community's adoption of a product has been recognized in studies of consumer behavior for quite some time (Reingen, Foster, Brown, \& Seidman, 1984). A few consumers gather a great number of friends in communities as a result of influential power, such that only a few popular and central consumers in a community are able to play the buzz agent role. Therefore, it is expected that buzz agents are central in a community and able to affect more consumer friends. We hypothesize the following:

$\mathbf{H}_{1 \mathbf{a}}$ : Buzz agents have a large number of members in their friendship community.

Social reputation and social support play an important role in a friend community. On the other hand, technical reputation and expertise play an important role in a community that shares technical information about brands. The technology domain community is able to assess one's expertise more accurately than self-evaluation. For the decision-making process, consumers may access technology experts to seek product advantages and technical details (Murphy et al., 2007). Previous research emphasizes the knowledge that consumers called market mavens have about products and places to shop, and mavens' tendency to initiate discussions with other consumers (Feick \& Price, 1987). Endorsement, another way for the buzz agent to express his/her product knowledge, is also a form of support or a statement of approval for a product, which can be rather persuasive. Firms engaging in 
WOMM initiatives need to encourage such public endorsement of brands. Leading researchers have referred to endorsers as market mavens (Feick \& Price, 1987) and opinion leaders (King \& Summers, 1970), whose influence extends across product categories and sources. Research has also shown that a reviewer's descriptive information about a book or a trip, for instance, is important to peer recognition and results in increased sales (Godes \& Mayzlin, 2004). The buzz agents with technical influence on their surroundings tend to be more persuasive and accepted by their community members. By demonstrating knowledge within the focal domain, the buzz agent is able to affect the perceived value of the contribution to other consumers (Weiss et al., 2008). To become a buzz agent, the candidate consumer has to listen carefully to the questions posed by other consumers and provide a compelling response. The technical information provided needs to be clear, credible and valuable, which makes other consumers return for additional information support. Thus, we hypothesize that:

H1b: Buzz agents have a large number of members in their technology community.

Buzz agents prefer to hang out with people like them. In WOM literature, this is called homophily and refers to the degree to which consumers are similar in terms of certain demographic attributes, such as age, gender, education, and social status (Brown \& Reingen, 1987). Buzz agents tend to be close to similar people and more likely to share values and beliefs with them. This builds up credibility and familiarity that are important components of product referral. Consumers tend to accept and adopt products that a homophilous buzz agent suggests or consumes. Therefore, we expect that:

H1c: Buzz agents have a large number of consumers like them in their community, considering age, gender and education.

Buzz agents have the tendency to influence consumers across different community domains. One domain may be the technical information while another may refer to personal issues. By having a consumer who is a friend and member of the technology community, buzz agents are able to have a message go through smoothly. Friend relationships are built on trust that tends to be conducive to any technical knowledge transfer (Beckman \& Haunschild, 2002). Consumers seeking information rely on the transparency and familiarity of friends and tend to be receptive to the information the buzz agent is providing. The influence across different community domains creates relational strength between consumers, which offers opportunities to request and provide support, and then build positive valence in the communication intent (Van den Bulte \& Wuyts, 2007). Therefore, we posit that:

H1d: Buzz agents have friends that are members of their technical community.

Brand management literature suggests that branding is critical to support all strong product selling propositions and guarantee a firm's market positioning (Keller, 2003). Brands are incorporated in our buzz agent profile in two ways: brand dissimilarity and brand expertise. First, consumers are more likely to buy products from a source (i.e. buzz agent) that actually uses the products on different occasions. Buzz agents own desired products, which enables credible referral. A recent study of WOM narratives showed the importance of owning a product to become credible to talk about it and influence another consumer (Kozinets et al., 2010). Second, brand expertise is critical. Understanding product advantages and details is necessary to consumers seeking advice. Buzz agents are deeply involved in searching for information and spending time shopping around, which allows them to acquire more general marketplace expertise. Thus, we expect that:

H2: Buzz agents (a) have brand dissimilarity from the target consumers and (b) are experts on products of interest.

In our attempt to profile the buzz agent, six control characteristics were also investigated. First, narcissism refers to a psychological portrait of individual self-admiration, leadership, arrogance and entitlement (Raskin \& Terry, 1988). Previous studies have shown that narcissists are characterized by their high levels of vanity, which implies interest in their own appearance and their desire to be the center of attention (Vazire, Naumann, Rentfrow, \& Gosling, 2008). Narcissists' exhibitionist tendencies lead them to become known for product referral in a provocative and attention-grabbing way. Narcissistic personality includes a grandiose sense of self-importance and a tendency to 
exaggerate their accomplishments and talents, and expect to be noticed as special even without appropriate achievement (John \& Robins, 1994). This grandiose personality shows a general tendency to over-communicate brand and product choices to others because there is a need to always selfenforce a high status image among other consumers.

We also controlled for four demographic characteristics of the buzz agent. Age reflects overall experience in purchasing and using brands while Education reflects a knowledge or skill acquired in formal ways in school. The profile includes a control for gender and income. High-income consumers become buzz agents by virtue of increased purchasing power and access to products that allow them to try out products and carefully assess the usage and quality.

\section{Research Method}

Our survey data collection followed Dillman's (2000) procedures. We developed a questionnaire by first identifying the relevant measurement instruments employed in previous research to capture the key characteristics of the buzz agent profile. We sought to carefully identify a product that suited our study, because not all product categories are suitable for a WOMM. First, the research team selected a short list of offering categories (mobile phones, computers and fitness centers), which are at the core of interest and represented a certain intensity of communication among consumers of the study population. We took into account categories that branded products are unique in some respect, be it in look, functionality, ease of use, efficacy, or price. We also considered and observed whether products were visible to some extent. Based on these issues, we talked informally to several potential respondents to assure product suitability in terms of frequency of casual conversations about the product and that the product somewhat required ex-ante information to support purchase decisions. We ruled out computers and fitness centers given the long cycle of product purchase and low brand visibility. This indicated that mobile phones are an appropriate product to carry out the research. We then consulted academics and experts in consumer markets to help us refine the questionnaire by looking at the wording of the questions, the overall content validity of the questions and the appropriateness of the focal product (mobile telephones). Once all suggestions and adjustments were incorporated, the questionnaire was pretested with 10 potential respondents. In the pretest, the focal product was revealed to be appropriate because of its functional (e.g. communication) and emotional (e.g. effect on life style in the community) appeal to the study population.

We chose business-school students as the study population, based on previous studies that have shown the importance of consumer market consumption for students and the controlled aspects of consumer demographics and behavior (Lester, Forman, \& Loyd, 2005; Wang, Baker, Wagner, \& Wakefield, 2007). An electronic questionnaire was emailed to 1,245 undergraduate students, who then received four follow-up e-mails in a three-week window. In addition, the school faculty was invited to encourage students to fill out the questionnaire. Our data collection effort yield a response rate of $44.8 \%$ (558); after excluding incomplete questionnaires, we had 542 usable responses.

The questionnaire comprises of various measurement instruments summarized in Table 1. In order to profile the buzz agent, we needed to identify the respondents in our sample perceived by others as a source of product referral. We asked respondents to name to whom they go to for information about telephone brands and devices. We then added 1 to every reference made about a respondent in our sample. For instance, respondent Peter informed in the survey that John (who also participated as a respondent in our survey) offered him information about telephone brands and devices. John's buzz agent variable will be 1 because John was named by Peter. If two other respondents named John as an information provider, John's buzz agent variable would total 3 . This procedure accounted for in-school referral sources and most importantly allowed us to control for common method bias because our dependent variable is provided by other respondents and is not defined in a self-reported question. Therefore, the construct of buzz agent was measured by the number of times the respondent was named by another respondent as a source of product referral. 
Table 1

Constructs and Items

\begin{tabular}{|c|c|}
\hline Variables & Question (Operationalization) \\
\hline \multicolumn{2}{|l|}{ Dependent Variable } \\
\hline Buzz Agent & $\begin{array}{l}\text { Number of respondents that named him/her. Based on the question: Considering the } \\
\text { people of the Business School, who do you go to for information about telephone } \\
\text { brands and devices? (added } 1 \text { each time an individual was named) }\end{array}$ \\
\hline \multicolumn{2}{|l|}{ Social community } \\
\hline Friends & $\begin{array}{l}\text { Number of respondents that named the buzz agent as a friend. Based on the question: } \\
\text { Considering the people of the Business School, list the names of your friends. (added } 1 \\
\text { each time an individual was named) }\end{array}$ \\
\hline Experts in Technology & $\begin{array}{l}\text { Number of respondents that named the buzz agent an expert in technology. Based on } \\
\text { the question: Considering the people of the Business School, list the name of the ones } \\
\text { that provide you with expert information about technology, telephone brands, devices } \\
\text { and applications. (added } 1 \text { each time an individual was named) }\end{array}$ \\
\hline People like me & $\begin{array}{l}\text { Number of buzz agent's attributes (education, age, gender) that are similar to the } \\
\text { respondents that named him/her as a buzz agent. (added } 1 \text { for each similar attribute } \\
\text { associated with an individual) }\end{array}$ \\
\hline $\begin{array}{l}\text { Friend experts in } \\
\text { technology }\end{array}$ & $\begin{array}{l}\text { Number of a respondents' friends that also named him/her an expert in technology. } \\
\text { (added } 1 \text { each time an individual was named a technology expert) }\end{array}$ \\
\hline \multicolumn{2}{|l|}{ Brand Attachment } \\
\hline Brand Similarity & $\begin{array}{l}\text { The total number of respondents that own a different telephone brand than the buzz } \\
\text { agent. (added } 1 \text { each time an individual was named as having a different phone brand) }\end{array}$ \\
\hline \multirow[t]{2}{*}{ Brand Expertise } & (7-point scale; very low - very high) \\
\hline & Please assess your expertise in telephone brands and devices. \\
\hline
\end{tabular}

Narcissism (7-point scale, strongly disagree - strongly agree).

1. I can become entirely absorbed in thinking about my personal affairs, my health, my cares or my relations to others. (reverse item)

2. My feelings are easily hurt by ridicule or the slighting remarks of others.

3. When I enter a room I often become self-conscious and feel that the eyes of others are upon me.

4. I dislike sharing the credit of an achievement with others. (reverse item)

5. I feel that I have enough on my hands without worrying about other people's troubles.

6. I feel that I am temperamentally different from most people.

7. I often interpret the remarks of others in a personal way.

8. I easily become wrapped up in my own interests and forget the existence of others.

9. I dislike being with a group unless I know that I am appreciated by at least one of those present.

10. I am secretly put out or annoyed when other people come to me with their troubles, asking me for my time and sympathy. 
Table 1 (continued)

\begin{tabular}{ll}
\hline \multicolumn{1}{c}{ Variables } & \multicolumn{1}{c}{ Question (Operationalization) } \\
\hline Age & The number of years of age as of the date of data collection. \\
Gender & 0 female, 1 male. \\
Education & Total number of years in the undergraduate program. \\
Income $(\ln )$ & Total income of student and parents. \\
\hline
\end{tabular}

Social community was comprised of four constructs: friend community, technology community, people like me and friends experts in technology. First, we asked respondents to name people that the respondent has interacted with in a friendship context by any means (e.g. face-to-face or online). We also asked respondents to name people that the respondent has interacted with in a technology context that includes telephone brands, device specifications and phone applications. These two instruments were employed to capture the friend and technology communities respectively. We then added 1 to every reference made to a respondent in our sample. Therefore, the construct of friend and technology community was measured by the number of times the respondent was named by another respondent as member of each community.

The construct of people like me is based on the homophily concept (Brown \& Reingen, 1987) that refers to the degree to which pairs of respondents are similar in terms of their attributes, in this case, education, age and gender. The construct of the respondent's named buzz agent adds 1 for each attribute (education, age and gender) match between the respondent and the respondent's named buzz agent. For instance, Peter informed that John is a buzz agent. Peter happens to be the same age and gender as John. In this instance, John's people like me entry will be 2 . We then go on and check all other respondents that named John to add up the entries to the people like me variable every time attributes match.

The construct of friend experts in technology refers to the ties one maintains with the same individual in both communities, friend and technology. For instance, Peter named the buzz agent John as a member of his friend community and also named John as member of his technology community. John's entry variable for friend experts in technology is 1 because he is Peter's friend expert in technology. We then checked all of John's other friends to find the ones that also named him as part of their technology community. Let us say that, apart from Peter, two more of John's friends named him as member of their technology community, then John's variable for friend experts in technology adds up to 3.

Brand attachment was measured by two constructs: brand dissimilarity and brand expertise. First, brand dissimilarity refers to the total number of respondents that own the same telephone brand as the buzz agent. For instance, Peter named John as the buzz agent (i.e. information provider about telephone brands and devices). John has an entry 1 for the variable brand dissimilarity because he owns a different phone brand than Peter's phone. Let us say that two other respondents, who named John as a buzz agent, owns a different phone brand. John's total entry will be 3 to the variable of brand dissimilarity. Second, brand expertise is a self-reported assessment of the knowledge respondents have about brands and devices of the focal product. We used one item of a 7-point scale ranging from very low to very high.

We also considered five control variables in our buzz agent profile. First, the construct of narcissism, follows Hendin and Cheek (1997) a 10-item measurement instrument that was refined from the original 40-item Narcissistic Personality Inventory to assess sub-clinical narcissism (Raskin \& Terry, 1988). Narcissism refers to a trait that encompasses inflated self-importance, vanity, selfconsciousness, conceit and selfishness. We employed the 10-item instrument of a 7-point Likert scale ranging from strongly disagree to strongly agree. The Cronbach's alpha coefficient for this instrument was 0.60, which meets the lower limit of acceptability (Hair, Anderson, Tatham, \& Black, 1998). Even though the Cronbach's alpha is not as high as desired, we decided to keep the integrity of the 
scale and use it as one of the control variables in the model estimation. The variable was calculated using the unweighted average of the items.

Four other control variables captured respondent demographics. The variable age describes the respondent's age in years. We also controlled for gender (using values of 0 for female and 1 for male). The control variable for education accounts for the total number of years in the university. Finally, the control variable income was defined as a continuous open-ended variable that accounts for the total income of the student and parents. We computed the log of the income variable to estimate the model.

Table 2 displays the mean, standard deviation and minimum/maximum values of all variables. The $90 \%$ percentile of the buzz agent variable was used to split the sample and emphasize the contrast between buzz agents $(n=69)$ and non-buzz agents $(n=473)$. The $p$-value tests if the mean of the samples buzz agent and non-buzz agent are equal (t-test) for each variable.

Table 2

\section{Descriptive Statistics}

\begin{tabular}{|c|c|c|c|c|c|c|}
\hline Variable & Sample & Mean & Std. Dev. & Min. & Max. & p-value \\
\hline Buzz agent & Total & 0.05 & 0.09 & 0.00 & 0.65 & \\
\hline \multicolumn{7}{|l|}{ Social Community } \\
\hline \multirow[t]{3}{*}{ Friend } & Buzz Agent & 0.18 & 0.11 & 0.00 & 0.55 & \\
\hline & Non-Buzz Agent & 0.09 & 0.09 & 0.00 & 0.55 & $<0.001$ \\
\hline & Total & 0.10 & 0.10 & 0.00 & 0.55 & \\
\hline \multirow[t]{3}{*}{ Technology expert } & Buzz Agent & 0.19 & 0.19 & 0.00 & 0.77 & \\
\hline & Non-Buzz Agent & 0.04 & 0.08 & 0.00 & 0.69 & $<0.001$ \\
\hline & Total & 0.06 & 0.11 & 0.00 & 0.77 & \\
\hline \multirow[t]{3}{*}{ People like me } & Buzz Agent & 0.28 & 0.42 & 0.00 & 1.00 & \\
\hline & Non-Buzz Agent & 0.16 & 0.33 & 0.00 & 1.00 & 0.030 \\
\hline & Total & 0.18 & 0.35 & 0.00 & 1.00 & \\
\hline \multirow[t]{3}{*}{ Friend experts in technology } & Buzz Agent & 0.15 & 0.20 & 0.00 & 0.50 & \\
\hline & Non-Buzz Agent & 0.11 & 0.17 & 0.00 & 0.50 & 0.090 \\
\hline & Total & 0.11 & 0.18 & 0.00 & 0.50 & \\
\hline \multicolumn{7}{|l|}{ Brand attachment } \\
\hline \multirow[t]{3}{*}{ Brand dissimilarity } & Buzz Agent & 0.70 & 0.46 & 0.00 & 1.00 & \\
\hline & Non-Buzz Agent & 0.54 & 0.50 & 0.00 & 1.00 & 0.010 \\
\hline & Total & 0.56 & 0.50 & 0.00 & 1.00 & \\
\hline \multirow[t]{3}{*}{ Brand expertise } & Buzz Agent & 3.13 & 1.57 & 0.00 & 5.00 & \\
\hline & Non-Buzz Agent & 2.19 & 1.70 & 0.00 & 5.00 & $<0.001$ \\
\hline & Total & 2.30 & 1.62 & 0.00 & 5.00 & \\
\hline \multicolumn{7}{|l|}{ Control variables } \\
\hline \multirow[t]{3}{*}{ Narcissism } & Buzz Agent & 3.10 & 0.59 & 0.00 & 4.20 & \\
\hline & Non-Buzz Agent & 2.99 & 0.72 & 0.00 & 4.40 & 0.163 \\
\hline & Total & 3.00 & 0.71 & 0.00 & 4.40 & \\
\hline
\end{tabular}


Table 2 (continued)

\begin{tabular}{|c|c|c|c|c|c|c|}
\hline Variable & Sample & Mean & Std. Dev. & Min. & Max. & p-value \\
\hline \multirow[t]{3}{*}{ Age } & Buzz Agent & 20.41 & 1.39 & 18.00 & 26.00 & \\
\hline & Non-Buzz Agent & 20.18 & 1.75 & 17.00 & 25.00 & 0.227 \\
\hline & Total & 20.21 & 1.71 & 17.00 & 26.00 & \\
\hline \multirow[t]{3}{*}{ Education } & Buzz Agent & 4.55 & 1.69 & 1.00 & 8.00 & \\
\hline & Non-Buzz Agent & 3.99 & 2.29 & 1.00 & 8.00 & 0.174 \\
\hline & Total & 4.06 & 2.23 & 1.00 & 8.00 & \\
\hline \multirow[t]{3}{*}{ Income } & Buzz Agent & 9.73 & 0.66 & 7.82 & 10.31 & \\
\hline & Non-Buzz Agent & 9.61 & 0.70 & 7.82 & 10.60 & 0.015 \\
\hline & Total & 9.62 & 0.69 & 7.82 & 10.60 & \\
\hline
\end{tabular}

Note. The 90\% percentile was used to split the sample in Buzz Agent $(n=69)$ and Non Buzz Agent $(n=473)$. The p-value tests if the means of the samples Buzz Agent and Non Buzz Agent are equal (t test) for each variable.

The descriptive statistics raise interesting points regarding the buzz agent profile. Buzz agents tend to show higher mean for all variables when compared to non-buzz agents in the sample. The significant (10\% level) mean differences are found in all constructs of social community and brand attachment as well as income. These significant mean-difference tests provide initial indication of how relevant such variables are for profiling buzz agents.

Table 3 displays the correlation matrix of all variables used in the profile. The coefficients are positive and significant between the buzz agent variable and all social community variables (Friend, Tech expert, People like me and Friend experts in tech). There are also significant positive correlation coefficients for buzz agent and the brand attachment variables (Brand dissimilarity and Brand expertise). In addition, the correlations between the measures show that there are no potential problems of pairwise collinearity that may preclude the use of any of the variables in the ordinary least square regression model for the buzz agent profile.

Table 3

\section{Correlation Matrix}

\begin{tabular}{|c|c|c|c|c|c|c|c|c|c|c|c|c|}
\hline & BA & & $\mathrm{Fr}$ & TE & Plm & $\mathrm{FTe}$ & $\mathrm{BD}$ & $\mathrm{BE}$ & $\mathrm{Nrc}$ & Age & $\mathrm{G}$ & Edu \\
\hline Buzz Agent (BA) & 1.00 & & & & & & & & & & & \\
\hline Friend (Fr) & $0.35 *$ & & & & & & & & & & & \\
\hline $\begin{array}{l}\text { Technology Expert } \\
\text { (TE) }\end{array}$ & $0.50 *$ & & $0.27 *$ & & & & & & & & & \\
\hline People like me (Plm) & $0.15^{*}$ & & $0.19 *$ & $0.12 *$ & & & & & & & & \\
\hline $\begin{array}{l}\text { Friend Tech expert } \\
(\mathrm{FTe})\end{array}$ & $0.10 *$ & & $0.09 *$ & $0.19 *$ & $0.24 *$ & & & & & & & \\
\hline $\begin{array}{l}\text { Brand Dissimilarity } \\
\text { (BD) }\end{array}$ & $0.15 *$ & & $0.14 *$ & 0.05 & $0.46^{*}$ & $0.15 *$ & & & & & & \\
\hline Brand Expertise (BE) & $0.22 *$ & - & 0.05 & $0.22 *$ & 0.11* & $0.11 *$ & 0.05 & & & & & \\
\hline Narcissism (Nrc) & 0.04 & - & 0.01 & $0.10 *$ & 0.05 & 0.05 & -0.05 & $0.17 *$ & & & & \\
\hline Age & 0.07 & & 0.03 & 0.03 & 0.01 & 0.05 & - 0.04 & 0.01 & 0.00 & & & \\
\hline Gender (G) & 0.04 & - & $0.20 *$ & $0.20 *$ & 0.03 & 0.02 & - $0.15^{*}$ & $0.12 *$ & $0.09 *$ & 0.05 & & \\
\hline Education (Edu) & $0.11 *$ & & $0.10 *$ & 0.07 & 0.05 & 0.06 & 0.02 & 0.01 & 0.02 & $0.73 *$ & 0.02 & \\
\hline Income (Inc) & 0.05 & - & 0.05 & 0.05 & 0.04 & 0.01 & 0.05 & - 0.01 & $0.12 *$ & - 0.11* & -0.05 & $-0.09 *$ \\
\hline
\end{tabular}

Note. $* \mathrm{p}<0.05$. 


\section{Results}

We aim to study the consumer who influences other consumers when picking a brand. This study supports firms in recruiting and selecting consumers as buzz agents to promote the firms' brands. Our data collection effort identifies the buzz agent by asking consumers to name other consumers that they rely on to gather information about a brand. This measure captures how consumers perceive others as a source of product referral. With such a buzz agent measurement, we pursue an analysis that enables identifying characteristics that lead consumers to be perceived as sources of product referral. We studied the buzz agent profile using ordinary-least-square regression model. The dependent variable is the buzz agent variable and the independent variables are characteristics of the social community and brand attachment as well as controls.

Table 4 summarizes the results of the analysis. The coefficients are reported with the |t-test| value in parentheses. The equation was statistically significant at the 0.01 level according to the F-test and residual plots of the estimation presented a random pattern as expected. In addition, the adjusted $\mathrm{R} 2$ for the equation is 0.337 , indicating that the model has an acceptable degree of explanatory power (Hair et al., 1998). The explanatory power of the equation and the pattern of the significant coefficients support the examination of individual coefficients to test the effects of each individual variable on the buzz agent variable.

Model 1 shows that buzz agents are embedded in communities with people that named him/her as a friend $(\mathrm{b}=.206, \mathrm{p}<.01)$ and a technology expert $(\mathrm{b}=.358, \mathrm{p}<.01)$. This provides support to $\mathrm{H}_{1 \mathrm{a}}$ and $\mathrm{H}_{1 \mathrm{~b}}$, which assert that buzz agents are popular and central in the two social communities. However, no significant evidence was found about buzz agents' ties in the communities to people like them or friends that are also technology experts. These results show no support for $\mathrm{H}_{1 \mathrm{c}}$ and $\mathrm{H}_{1 \mathrm{~d}}$, suggesting that the power of buzz agents lie in the number of consumers in the community rather than the kind of consumers in the community. For spreading a message, buzz agents do not necessarily look for particular consumers. The aim is to reach as many people as possible.

Table 4

Results: Buzz Agent Profile

\begin{tabular}{lcc}
\hline Variable & Hypothesis & $\begin{array}{c}\text { Buzz Agent } \\
\text { Model 1 }\end{array}$ \\
\hline Social Community & & $\mathbf{. 0 6}(\mathbf{4 . 3 7})^{* *}$ \\
$\quad$ Friend & $\mathrm{H} 1 \mathrm{a}$ & $\mathbf{3 5 8}(\mathbf{8 . 6 6})^{* *}$ \\
Technology expert & $\mathrm{H} 1 \mathrm{~b}$ & $.013(1.20)$ \\
People like me & $\mathrm{H} 1 \mathrm{c}$ & $-.019(.94)$ \\
$\quad$ Friend experts in technology & $\mathrm{H} 1 \mathrm{~d}$ & \\
Brand Attachment & & $\mathbf{. 0 1 2}(\mathbf{1 . 9 8})^{*}$ \\
$\quad$ Brand dissimilarity & $\mathrm{H} 2 \mathrm{a}$ & $\mathbf{. 0 0 7}(\mathbf{2 . 8 5})^{* *}$ \\
$\quad$ Brand expertise & $\mathrm{H} 2 \mathrm{~b}$ & \\
Control Variables & & $-.005(1.13)$ \\
Narcissism & & $.001(.51)$ \\
Age & & $-.002(.24)$ \\
$\quad$ Gender & & \\
\hline
\end{tabular}


Table 4 (continued)

\begin{tabular}{|c|c|c|}
\hline Variable & Hypothesis & $\begin{array}{c}\text { Buzz Agent } \\
\text { Model } 1\end{array}$ \\
\hline Education & & $.002(1.21)$ \\
\hline Income & & $.011(2.61)^{* * *}$ \\
\hline Constant & & $-140(.07)^{*}$ \\
\hline $\mathrm{R}^{2}$ & & .350 \\
\hline Adjusted $\mathrm{R}^{2}$ & & .337 \\
\hline F-statistic & & $25.91 * *$ \\
\hline
\end{tabular}

Note. |t-values $\mid$ in parentheses. Buzz agent is the dependent variable.

Buzz agents have significant characteristics of brand attachment. Buzz agents have dissimilar brands from the ones owned by influenced consumers as suggested in $\mathrm{H}_{2 \mathrm{a}}(\mathrm{b}=.012, \mathrm{p}<.05)$. There is an aspirational impact of products owned by buzz agents, because buzz agents and the influenced consumers have different product brands. It is likely that buzz agents own products that the people in the community are willing to have. In addition, buzz agent's self-evaluation about brand expertise is also significant $(\mathrm{b}=.07, \mathrm{p}<.01)$. Consumers go for information about brands to specific consumers (i.e. buzz agents), who are confident about his/her own expertise.

In addition, only one control characteristic of buzz agent is significant. High-income buzz agents tend to influence other consumers more $(\mathrm{b}=.09, \mathrm{p}<.01)$. This impact suggests that buzz agents with more purchasing power exercise higher influence on consumers' buying decisions.

\section{Post hoc analysis}

The analysis of the buzz agent profile presented in the previous section shed light on the characteristics of the consumer who is perceived by other consumers as a source of product referral. One natural concern is whether the control characteristics of narcissism somehow play a role in the buzz agent profile. Previous WOM literature suggested that narcissism would influence communication among consumers (Baumgarten, 1975; John \& Robins, 1994). Following this concern, we decided to conduct a series of post hoc analysis to further explore narcissistic consumers (Table 5).

Table 5

Post Hoc: Buzz Agent Profile

\begin{tabular}{|c|c|c|c|}
\hline \multirow[t]{2}{*}{ Variable } & \multicolumn{3}{|c|}{ Buzz Agent } \\
\hline & Model 2 & Model 3 & Model 4 \\
\hline \multicolumn{4}{|l|}{ Social Community } \\
\hline Friend & - .10 (.64) & $.20(5.45)^{* *}$ & $.20(5.36)^{* *}$ \\
\hline Technology expert & $.41(1.97)^{*}$ & $.35(10.55)^{* * *}$ & $.35(9.58) * *$ \\
\hline People like me & $.01(1.07)$ & $.01(1.43)$ & $.01(1.42)$ \\
\hline Friend experts in technology & $-.02(.94)$ & - .02 (.99) & - .02 (1.27) \\
\hline \multicolumn{4}{|l|}{ Brand Attachment } \\
\hline Brand dissimilarity & $.01(1.61)$ & - .01 (1.98)* & - .01 (1.99)* \\
\hline Brand expertise & $.01(2.94) * *$ & $.01(3.14) * *$ & $.01(3.13) * *$ \\
\hline
\end{tabular}


Table 5 (continued)

\begin{tabular}{|c|c|c|c|}
\hline \multirow[t]{2}{*}{ Variable } & \multicolumn{3}{|c|}{ Buzz Agent } \\
\hline & Model 2 & Model 3 & Model 4 \\
\hline \multicolumn{4}{|l|}{ Narcissism } \\
\hline Narcissism & - .01 $(3.27)^{* *}$ & & \\
\hline Self-importance & & $-.00(1.09)$ & $-.01(1.37)$ \\
\hline Self-conscious & & $.00(.79)$ & $-.01(1.76)$ \\
\hline Conceit & & $-.00(.33)$ & $.00(.22)$ \\
\hline \multicolumn{4}{|l|}{ Moderating Effects of Narcissism } \\
\hline Friend $*$ Narcissism & $.10(1.97)^{*}$ & & \\
\hline Technology expert * Narcissism & $-.02(.23)$ & & \\
\hline Friend $*$ Self-importance & & & $.08(2.48)^{* *}$ \\
\hline Friend $*$ Self-conscious & & & $.07(2.01)^{* *}$ \\
\hline Friend $*$ Conceit & & & - .01 (.31) \\
\hline Technology expert $*$ Self-importance & & & $-.08(2.86)^{* *}$ \\
\hline Technology expert $*$ Self-conscious & & & $.07(2.02)^{*}$ \\
\hline Technology expert $*$ Conceit & & & $-.03(.70)$ \\
\hline \multicolumn{4}{|l|}{ Control Variables } \\
\hline Age & $.00(.54)$ & $.00(.49)$ & $.00(.50)$ \\
\hline Gender & - .00 (.49) & $.00(.12)$ & $-.00(.26)$ \\
\hline Education & $.00(1.16)$ & $.00(.85)$ & $.00(.99)$ \\
\hline Income & $.01(2.59) * *$ & $.01(2.34)^{* *}$ & $.01(2.15)^{* *}$ \\
\hline Constant & - $4.10(3.59)^{* *}$ & - $4.85(4.41)^{* * *}$ & - $5.07(4.46)^{* *}$ \\
\hline $\mathrm{R}^{2}$ & .360 & .363 & .384 \\
\hline Adjusted $\mathrm{R}^{2}$ & .344 & .342 & .361 \\
\hline F-statistic & $22.45^{* * *}$ & $21.27 * *$ & $16.26^{* * *}$ \\
\hline
\end{tabular}

Note. $|t-v a l u e s|$ in parentheses. Buzz agent is the dependent variable in all models. $* \mathrm{p}<.05 ; * \mathrm{p}<.01$.

First, we estimated model 2, which replicates model 1 with the moderating effects of social community and narcissism. One might suggest that narcissistic consumers will be keener to show off in the community. Results of model 2 show that narcissistic buzz agents tend to be seen more significantly in the friend community $(\mathrm{b}=.10, \mathrm{p}<.05)$. This suggests that narcissism plays a facilitating role in the friend community. Additionally, we further analyzed the narcissism construct in some dimensions by looking at an exploratory factor analysis (Table 6). Three factors, with a total explained variance of $47.6 \%$, are identified by setting Kaiser's eigenvector greater than 1 . The items loaded in factor 1 indicate a disregard for other people and an inflated feeling of self-importance. The items loaded in factor 2 indicate concern about what other people say and think that creates a self-conscious sentiment. Factor 3 items suggest an attitude of thinking that the person is better than anyone else is. This resembles a sentiment of conceit. By using the three different factors of narcissism, we estimated model 3 with the main variables and model 4 with moderating effects. 
Table 6

Post Hoc: Narcissism Factor Analysis

\begin{tabular}{|c|c|c|c|}
\hline & Factor 1 & Factor 2 & Factor 3 \\
\hline & Self-importance & Self-conscious & Conceited \\
\hline $\begin{array}{l}\text { 1. I can become entirely absorbed in thinking about } \\
\text { my personal affairs, my health, my cares or my } \\
\text { relations to others. }\end{array}$ & -.119 & -.097 & .874 \\
\hline $\begin{array}{l}\text { 2. My feelings are easily hurt by ridicule or the } \\
\text { slighting remarks of others. }\end{array}$ & -.188 & .757 & -.066 \\
\hline $\begin{array}{l}\text { 3. When I enter a room I often become self-conscious } \\
\text { and feel that the eyes of others are upon me. }\end{array}$ & .112 & .630 & .092 \\
\hline $\begin{array}{l}\text { 4. I dislike sharing the credit of an achievement with } \\
\text { others. }\end{array}$ & -.594 & -.187 & -.016 \\
\hline $\begin{array}{l}\text { 5. I feel that I have enough on my hands without } \\
\text { worrying about other people's troubles. }\end{array}$ & .662 & -.076 & -.022 \\
\hline $\begin{array}{l}\text { 6. I feel that I am temperamentally different from most } \\
\text { people. }\end{array}$ & .187 & .333 & .402 \\
\hline $\begin{array}{l}\text { 7. I often interpret the remarks of others in a personal } \\
\text { way. }\end{array}$ & .127 & .708 & -.026 \\
\hline $\begin{array}{l}\text { 8. I easily become wrapped up in my own interests and } \\
\text { forget the existence of others. }\end{array}$ & .647 & -.039 & .316 \\
\hline $\begin{array}{l}\text { 9. I dislike being with a group unless I know that I am } \\
\text { appreciated by at least one of those present. }\end{array}$ & .446 & .310 & .061 \\
\hline $\begin{array}{l}\text { 10. I am secretly put out or annoyed when other } \\
\text { people come to me with their troubles, asking me for } \\
\text { my time and sympathy. }\end{array}$ & .663 & .001 & -.170 \\
\hline Extracted explained variance (\%) & 21.5 & 15.6 & 10.6 \\
\hline
\end{tabular}

Note. Extraction Method: Principal Component Analysis. Rotation Method: Varimax with Kaiser Normalization.

The results in model 3 (Table 5) show no additional significant effect of the narcissism factors. However, the results in model 4 (Table 5) show interesting findings. Buzz agents displaying an inflated self-importance $(b=.08, p<.01)$ and self-consciousness $(b=.07, p<.01)$ increase in the number of members in the friend community. Friends appear to appreciate this kind of buzz agents. Results also show that self-conscious buzz agents are embedded in large technology expert communities $(b=.07, p<.05)$. The self-conscious compound of narcissism is an alternative explanation for the concern about others' opinions combined with the willingness to communicate and persuade others. Self-conscious buzz agents boost their privileged position in the social communities. Self-important buzz agents find trouble in the technology expert community $(b=-.08, p<.01)$. Influenced consumers may perceive self-important buzz agents as dilettantes, which causes the seeker to cast doubt on the veracity of the provider's knowledge in the expertise domain.

\section{Discussion and Managerial Implications}

We address in this paper scholars' and practitioners' call for research to better understand the consumers who play the role of buzz agent (Brown \& Reingen, 1987; Joachimsthaler, 2010; Kumar, Petersen, \& Leone, 2007; Schmitt et al., 2011). In the consumer-to-consumer context, firms can 
deploy initiatives of word of mouth marketing to stimulate brand endorsement for instance (Dye, 2000). Few consumers are truly prone to spread the brand message to a number of other consumers and effectively persuade others to purchase the brand. In this paper, we profile these few powerful consumers who we call buzz agents.

Figure 2 displays the profile of buzz agents. This profile contains characteristics such as the buzz agent's friend community, which accounts for the number of friends who go to him/her to access information about brands. We also look at the number of other consumers who believe the buzz agent is a technology expert. The profile included whether buzz agents are likely to stick to community members who are more like him/her. In social communities, having the buzz agent reputation across different domains may be of importance. In the profile, we assessed the number of buzz agent's friends who are also part of the technology community. In addition, brands are a key to word of mouth and two issues were profiled as brand attachment characteristics. First, consumers perceive any testimony or referral to be credible when the buzz agent owns the brand. One might even suggest a certain degree of wishful brand desire. Buzz agents with dissimilar brands tend to influence other consumers more. Second, brand expertise also matters. In the profile, we assess the extent to which other consumers perceive a buzz agent as an expert. Considering these characteristics of the buzz agent, we discuss in this paper the profile of the consumer that is a source of product referral.

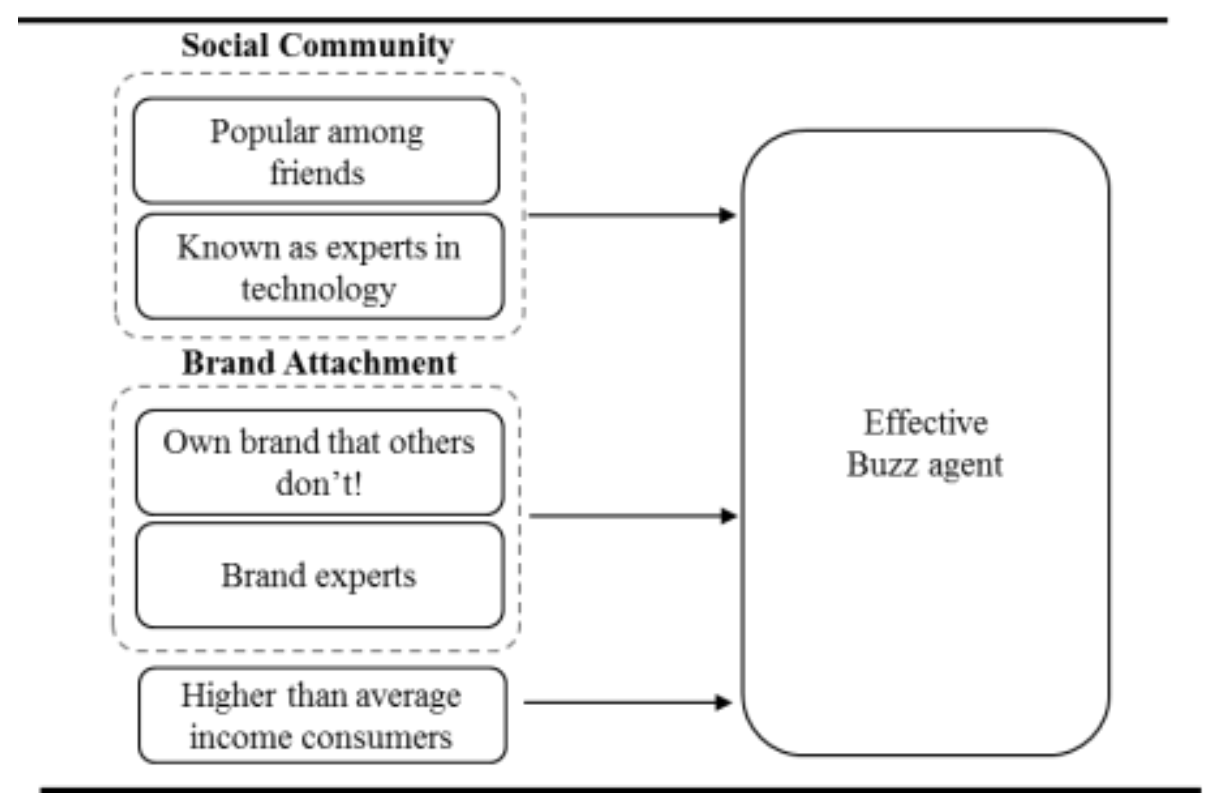

Figure 2. Profile of the Buzz Agent

Based on the buzz agent profile, we collected data and present evidence that buzz agent's social community play an important role in increasing product referral. Our results show that buzz agents are consumers with a large number of other consumers naming them as friends and technology experts. This result provides evidence for previous research suggesting that consumers must explore the breadth of membership communities (Weiss et al., 2008). There is also evidence that brand dissimilarity and brand expertise are critical for the buzz agent. Knowledgeable buzz agents tend to be effective by conveying the message about a brand and more importantly by owning the brand (Kozinets et al., 2010).

Our research offers contributions to the literature on word of mouth and word of mouth marketing (WOMM). First, we developed a buzz agent profile based on WOM literature, which integrated social community and brand attachment. This profile effort fills the gap of understanding the particular consumer who supports WOMM initiatives (Kumar, Petersen, \& Leone, 2010). Second, we illustrate the importance of social communities for a buzz agent to be influential. Our study shows that the higher the number of community members who named a particular consumer (i.e. buzz agent) a friend and a tech expert, the greater the power of this particular consumer to influence another consumer. In the consumer-to-consumer context, the communities create opportunities for a few 
consumers to attract attention and become unique and relevant (Cheema \& Kaikati, 2010). The way buzz agents navigate in the community affects members' perception of reputation and the credibility of any shared information about a brand or product usage (Patterson, 2007). Third, a buzz agent is familiar with a brand as well as with product usage and features. This intimacy is a key to persuading another consumer to adopt a new technology or brand (Goldenberg et al., 2009). There is also the aspirational touch to buzz agents' products because they already own the brand and talk to other consumers as an acknowledged user. Finally, we also contribute to the study of WOM by developing a novel survey instrument to identify the individual who is perceived as the source of product referral. This instrument requires respondents to name particular consumers who are able to influence purchase decisions. By identifying the particular consumers with the most influential power (i.e. product referral), we were able to profile the key consumer characteristics of buzz agents.

Our findings reveal interesting managerial implications. Building strong social community is an advantage for both the buzz agent and the firm's marketing effort because it strengthens the relationship between brand and consumers over time. It also becomes hard for a competitor to attract consumers who are tightly locked in to the social norms and values of the community (Kozinets et al., 2010). Additionally, firms may look into our final profile to more accurately identify and select consumers who have power to influence others. Our study highlights the importance of being popular and central in the friend and technology expert community, as well as the importance of brand attachment. Every significant individual characteristic may be assessed to identify potential candidates as effective buzz agents. As a cautionary tale, our results may serve as guidelines for recruiting and selecting consumers to be part of a marketing campaign designed to introduce or promote telephone products.

The evidence gathered in our study indicates opportunities for future research. Firms rely on WOM and recruit consumers as volunteer buzz agents (Court et al., 2005; Kaikati \& Kaikati, 2004), who are often unpaid, ostensibly engaging in buzz communication for psychosocial benefits (Bughin, Doogan, \& Vetvik, 2010). We included narcissism as a control in the profile and found some evidence in the post-hoc analysis about self-conscious consumers. Future research could address in detail other psychological drivers such as self-confidence or self-esteem of buzz agents, for instance in experimental design (for a comprehensive list see McCrae \& Costa, 1987). Further studies on WOMM could also improve our understanding of the structure of WOM-contact community. Previous studies have investigated brand-building social networks (e.g., Brown \& Reingen, 1987; Reingen et al., 1984). Future studies may address other natures of social networks. In addition, our study focused on mobile telephones and a studied population composed of undergrad business-school students. By controlling for the product and the studied population, we avoided interpretation response bias across respondents. One may suggest that technology communities will affect differently or have no effect on less technology-driven consumer good markets (e.g. clothes). Future studies may look at other product categories and services as well as other populations to provide external validity to the buzz agent profile.

\section{References}

Baumgarten, S. A. (1975). The innovative communicator in the diffusion process. Journal of Marketing Research, 12(1), 12-18. doi: 10.2307/3150653

Beckman, C., \& Haunschild, P. (2002). Network learning: the effects of heterogeneity of partner's experience on corporate acquisitions. Administrative Science Quarterly, 47(1), 92-124. doi: $10.2307 / 3094892$

Brooks, R. C., Jr. (1957). 'Word-of-mouth' advertising in selling new products. Journal of Marketing, 22(2), 154-161. doi: 10.2307/1247212 
Brown, J. J., \& Reingen, P. H. (1987). Social ties and word-of-mouth behavior. Journal of Consumer Research, 14(3), 350-362. doi: 10.1086/209118

Bughin, J., Doogan, J., \& Vetvik, O. J. (2010, April). A new way to measure word-of-mouth marketing. McKinsey Quarterly, 2, 113-116.

Cheema, A., \& Kaikati, A. M. (2010). The effect of need for uniqueness on word of mouth. Journal of Marketing Research, 47(3), 553-563. doi: 10.1509/jmkr.47.3.553

Chevalier, J. A., \& Mayzlin, D. (2006). The effect of word of mouth on sales: online book reviews. Journal of Marketing Research, 43(3), 345-354. doi: 10.1509/jmkr.43.3.345

Court, D. C., Gordon, J. W., \& Perrey, J. (2005, May). Boosting returns on marketing investment. McKinsey Quarterly, 1-7.

Dichter, E. (1966). How word-of-mouth advertising works. Harvard Business Review, 44, 147-166.

Dillman, D. A. (2000). Mail and internet surveys: the tailored design method. New York: John Wiley \& Sons.

Dye, R. (2000). The buzz on buzz. Harvard Business Review, 78(6), 139-146.

Feick, L. F., \& Price, L. L. (1987). The market maven: a diffuser of marketplace information. Journal of Marketing, 51(1), 83-97. doi: 10.2307/1251146

Frenzen, J., \& Nakamoto, K. (1993). Structure, cooperation, and the flow of market information. Journal of Consumer Research, 20(3), 360-375. doi: 10.1086/209355

Gatignon, H., \& Robertson, T. S. (1986). An exchange theory model of interpersonal communication. In R. J. Lutz (Ed.), Advances in consumer research (Vol. 13, pp. 534-538). Provo, UT: Association for Consumer Research.

Godes, D., \& Mayzlin, D. (2004). Using online conversations to study word of mouth communication. Marketing Science, 23(4), 545-560. doi: 10.1287/mksc.1040.0071

Goldenberg, J., Han, S., Lehmann, D. R., \& Hong, J. W. (2009). The role of hubs in the adoption process. Journal of Marketing, 73(2), 1-13. doi: 10.1509/jmkg.73.2.1

Haenlein, M., \& Libai, B. (2013). Targeting revenue leaders for a new product. Journal of Marketing. 77(3), 65-80. doi: 10.1509/jm.11.0428

Hair, J. F., Anderson, R., Tatham, R. L., \& Black, W. C. (1998). Multivariate data analysis. Upper Saddle River: Prentice Hall.

Hendin, H. M., \& Cheek, J. M. (1997). Assessing hypersensitive narcissism: a reexamination of Murray's narcism scale. Journal of Research in Personality, 31(4), 588-599. doi: 10.1006/jrpe.1997.2204

Joachimsthaler, E. (2010). Social currency. New York: Vivaldi Partners.

John, O. P., \& Robins, R. W. (1994). Accuracy and bias in self-perception: individual differences in self-enhancement and the role of narcissism. Journal of Personality and Social Psychology, 66(1), 206-219. doi: 10.1037/0022-3514.66.1.206

Kaikati, A. M., \& Kaikati, J. G. (2004). Stealth marketing: how to reach consumers surreptitiously. California Management Review, 46(4), 6-22. doi: 10.1225/CMR288

Keller, K. L. (2003). Brand synthesis: the multi-dimensionality of brand knowledge. Journal of Consumer Research, 29(4), 595-600. doi: 10.1086/346254 
King, C. W., \& Summers, J. O. (1970). Overlap of opinion leadership across consumer product categories. Journal of Marketing Research, 7(1), 43-50.

Kozinets, R. V., Valck, K. de, Wojnicki, A. C., \& Wilner, S. J. S. (2010). Networked narratives: understanding word-of-mouth marketing in online communities. Journal of Marketing, 74(2), 71-89. doi: 10.1509/jmkg.74.2.71

Kumar, V., Petersen, J. A., \& Leone, R. P. (2007). How valuable is word of mouth?. Harvard Business Review, 85, 139-146.

Kumar, V., Petersen, J. A., \& Leone, R. P. (2010). Driving profitability by encouraging customer referrals: who, when, and how. Journal of Marketing, 74(5), 1-17. doi: 10.1509/jmkg.74.5.1

Lester, D. A., Forman, A. M., \& Loyd, D. (2005). Internet shopping and buying behavior of college students. Services Marketing Quarterly, 27(2), 123-138. doi: 10.1300/J396v27n02_08

Mazar, N., Amir, O., \& Ariely, D. (2008). The dishonesty of honest people: a theory of self-concept maintenance. Journal of Marketing Research, 45(6), 633-644. doi: 10.1509/jmkr.45.6.633

McCrae, R. R., \& Costa, P. T. (1987). Validation of the five-factor model of personality across instruments and observers. Journal of Personality and Social Psychology, 52(1), 81-90. doi: $10.1037 / 0022-3514.52 .1 .81$

Murphy, L., Mascardo, G., \& Benckendorff, P. (2007). Exploring word-of-mouth influences on travel decisions: friends and relatives vs. other travelers. International Journal of Consumer Studies, 31(5), 517-527. doi: 10.1111/j.1470-6431.2007.00608.x

Nam, H., \& Kannan, P. K. (2014). The informational value of social tagging networks. Journal of Marketing, 78(4), 21-40. doi: 10.1509/jm.12.0151

Patterson, I. (2007). Information sources used by older adults for decision making about tourist and travel destinations. International Journal of Consumer Studies, 31(5), 528-533. doi: 10.1111/j.1470-6431.2007.00609.x

Raskin, R., \& Terry, H. (1988). A principal-components analysis of the narcissistic personality inventory and further evidence of its construct validity. Journal of Personality and Social Psychology, 54(5), 890-902. doi:10.1037/0022-3514.54.5.890

Reingen, P. H., Foster, B. L., Brown, J. J., \& Seidman, S. B. (1984). Brand congruence in interpersonal relations: a social network analysis. Journal of Consumer Research, 11(3), 771783.

Schmitt, P., Skiera, B., \& Van den Bulte, C. (2011). Referral programs and customer value. Journal of Marketing, 75(1), 46-59. doi: 10.1509/jmkg.75.1.46

Van den Bulte, C., \& Wuyts, S. (2007). Social networks and marketing. Relevant knowledge series. Cambridge, Massachusetts: Marketing Science Institute.

Vazire, S., Naumann, L. P., Rentfrow, P. J., \& Gosling, S. D. (2008). Portrait of a narcissist: manifestations of narcissism in physical appearance. Journal of Research in Personality, 42(6), 1439-1447. doi: 10.1016/j.jrp.2008.06.007

Wang, L. C., Baker, J., Wagner, J. A., \& Wakefield, K. (2007). Can a retail web site be social?. Journal of Marketing, 71(3), 143-157. doi: 10.1509/jmkg.71.3.143

Weiss, A. M., Lurie, N. H., \& MacInnis, D. J. (2008). Listening to strangers: whose responses are valuable, how valuable are they, and why?. Journal of Marketing Research, 45(4), 425-436. doi: $10.1509 / j m k r .45 .4 .425$ 
You, Y., Vadakkepatt, G. G., \& Joshi, A. M. (2015). A meta-analysis of electronic word-of-mouth elasticity. Journal of Marketing, 79(2), 19-39. doi: 10.1509/jm.14.0169

\section{Authors' Profiles}

Danny Pimentel Claro

Rua Quatá, 300, 04546-042, São Paulo, SP, Brazil. E-mail address: danny@insper.edu.br

Adriana Bruscato Bortoluzzo

Rua Quatá, 300, 04546-042, São Paulo, SP, Brazil. E-mail address: adrianab@insper.edu.br 